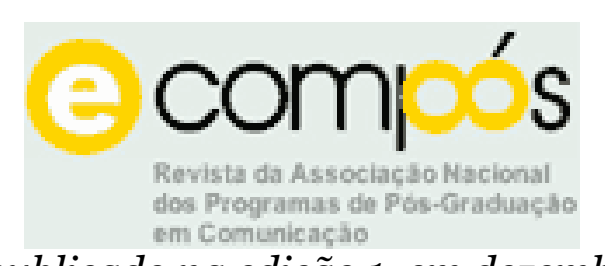

Este artigo foi publicado na edição 1, em dezembro de 2004, da revista eletrônica e-compós: http://www.compos.org.br/e-compos

\title{
A EXPERIÊNCIA ESTÉTICA E A VIDA ORDINÁRIA
}

César Guimarães

UFMG

\section{O que ainda podemos esperar da experiência estética?}

Algumas das obras artísticas mais significativas da Modernidade, assim como o pensamento crítico que elas geraram, legaram-nos uma figura da experiência estética cujo caráter paradoxal permanece não-resolvido até hoje. Segundo Karl Heinz Bohrer, as noções de "iluminação profana" e de "outro estado", cunhadas respectivamente por Walter Benjamin e Robert Musil, designam "um estado mental ou intelectual que definitivamente transcendem o comumcotidiano, mas insistem, ao mesmo tempo, no expressamente intramundano". ${ }^{1}$ Diversos são os exemplos que nos vêem à mente e, e lembramos logo dos momentos epifânicos das narrativas de James Joyce e Clarice Lispector. Entre tantos exemplos possíveis, recuo um pouco mais no tempo e escolho um poema de Emily Dickinson que exibe - com rara precisão - esse tipo de experiência:

Flores - bem - se pode alguém

O êxtase definir -

Meio um transporte - meio um transtorno -

Quando as flores humilham os homens:

Aquele que encontra a fonte

De onde voltam as enchentes -

\footnotetext{
${ }^{1}$ BOHRER, Karl Heinz. O ético no estético. ROSENFIELD, Denis L. (Org) Ética e estética. Rio de Janeiro: Jorge Zahar, 2001, p. 18.
} 
Eu lhe darei todas as margaridas

Que balançam sobre o monte.

Muita paixão em suas faces

Para o simples peito meu -

Borboletas em São Domingo

Vagando pelo escuro céu -

Tem um sistema estético -

Tão superior ao meu. ${ }^{2}$

A crer nos argumentos apresentados por Martin Seel em L'art de diviser - le concept de rationalité esthétique, poemas como esse de Emily Dickinson alimentaram, junto a acertas abordagens dos objetos artísticos, a vontade de transcender a dimensão estética em favor de uma diferenciação inédita do conhecimento - singular e enfático - proporcionado pelas obras, tornado inteiramente irredutível às situações que conhecemos no curso costumeiro da vida. Como definir, afinal, essa revelação extática - "entre transporte e transtorno" - que desloca o sujeito da sua percepção e atitude habituais e o retira dos limites do mundo conhecido? Como é que o discurso filosófico, através de uma disciplina em particular, a Estética, buscou dar conta de uma experiência como esta?

Segundo Martin Seel, a concepção "fundamentalista" da experiência estética - adotada por Heidegger, Adorno e Gadamer, ao lado do jovem Schelling e do jovem Hegel - nega a existência de uma racionalidade estética em nome de um conceito integral de verdade e de conhecimento, revelados unicamente pelas obras de arte. Já a concepção “purista” - presente em Nietzsche, Valéry, Bataille, Iser e Bubner, além do Kant da Analítica da Faculdade de Juízo Estética - nega a racionalidade estética em nome de um conceito exclusivo da reflexão pura ou da intensidade inefável na qual a percepção estética se liberta das significações e dos

\footnotetext{
${ }^{2}$ A tradução é de Fernanda Mourão e foi publicada em CASTELLO BRANCO, Lúcia. A branca dor da escrita. Três tempos com Emily Dickinson. Rio de Janeiro: 7 Letras; Belo Horizonte: Poslit-UFMG, 2003, p. 83. Eis o original: Flowers - Well - if anybody/ Can the ectasy define -/ Half a transport - half a trouble /With which flowers humble men:/Anybody find the fountain/ From which floods so contra flow -/ I will give him all the Daisies/ Which upon the hillside blow.// Too much pathos in their faces/ For a simple breast like mine - / Butterflies from St. Domingo/ Cruising around the purple line -/Have a system of aesthetics - Far superior to mine.
} 
conceitos de uma compreensão cognitiva do mundo3. A despeito das nuances que esta classificação comporta, ambas as concepções coincidem em considerar a arte como cognoscível e, como tal, indicador de outra coisa que não ela mesma: para a Estética, a arte é um meio para o aparecimento da verdade, sublinha Iser.4

Em oposição a essas duas concepções que fizeram da estética o "outro da Razão", Seel, na esteira da Teoria da Ação Comunicativa, adota um "programa forte” de definição da racionalidade estética e procura caracterizá-la em sua relação conflituosa e concorrente - sem solução de harmonia - com os demais tipos de racionalidade. Ao adotar uma definição plural e aberta da Razão, que não governa soberanamente os diferentes tipos de racionalidade que a animam, Seel reivindica que a experiência estética deve ser compreendida por meio da sua vizinhança paralela e contrastante - com a rede de assimilação não estética da realidade.5 Para tanto, a experiência estética é destituída daquela "transcendência na imanência” de que nos fala Bohrer e inserida em um contexto específico de ação e de comunicação, isto é, em uma situação na qual o sujeito é levado a desenvolver uma compreensão pragmático-performativa do objeto que lhe é apresentado.

A adoção de uma atitude em relação a um objeto acarreta três implicações 1) a adoção de uma regra que, à maneira de uma resposta prática, guia nosso comportamento frente aos objetos (orientação volitiva); 2) a pressuposição de razões que guiam nossa forma de agir (orientação cognitiva); 3) uma disposição emotiva diante dos estados de fato a que a atitude se refere (orientação afetiva). Como resultado de uma experiência, a atitude carrega um conhecimento que é pessoal, em grande parte implícito, eminentemente prático e que só pode ser criticado ou retificado a partir de uma situação concreta que problematiza a maneira até então habitual com que o sujeito agia. Embora o suporte inicial da experiência estética seja o indivíduo, ela possui uma dimensão que é social e não simplesmente psicológica. A atitude possui uma função organizadora do sentido: diante de situações experimentadas concretamente, ela concerne tanto àquelas

\footnotetext{
${ }^{3}$ SEEL, Martin. L'art de diviser. Le concept de rationalité esthétique. Paris: Armando Colin, 1993, p. 46.

${ }^{4}$ ISER, Wolfgang. O ressurgimento da estética. ROSENFIELD, Denis L. (Org) Ética e estética. Rio de Janeiro: Jorge Zahar, 2001, p. 38.

${ }^{5}$ SEEL. L'art de diviser. Le concept de rationalité esthétique, p. 27.
} 
regras e convicções que nos governam imediata e intuitivamente (e das quais não duvidamos), quanto à significação - aberta à problematização - que passamos a conceder aos novos fenômenos que experimentamos.

Distinta de outros tipos de atitude (teórica, instrumental, moral e preferencial), a atitude estética é "guiada pelo interesse concedido à presentificação de conteúdos da experiência que, no interior de uma dada forma de vida, tornam perceptíveis a atualidade e a disposição interna de nossa própria experiência”. ${ }^{6}$ Por presentificação dos conteúdos da experiência, Seel entende um modo de acesso a uma situação feito de maneira alusiva, não direto, e necessariamente dependente do contexto. Os conteúdos de experiência conhecidos por meio da percepção estética, embora possam ser comunicados a um terceiro, não são alcançados por meio de uma compreensão cognitivo-proposicional.

O que é específico da experiência estética é o fato da comunicação de experiências se realizar por meio de performances artificiais: "o objeto artístico torna-se o medium de uma presentificação de experiências”, sem que ele mesmo esteja inserido em um contexto de experiências determinado: são aqueles que se engajam na experiência estética que se servem deste medium para tomar consciência de suas próprias experiências. Entretanto, o que os sujeitos fazem ao experimentarem algo esteticamente não é simplesmente "filtrar" os conteúdos de experiência presentificados pelo objeto por meio da sua própria experiência (já constituída), pois não podem ignorar a organização significante interna dos objetos. A percepção estética coloca em jogo uma relação experimental entre a significação dos objetos estéticos e a nossa experiência presente, ao permitir fazermos uma experiência com as experiências presentificadas pelos objetos. Ou nos termos de Seel: "É estético o fato de fazer experiência das possibilidades de ter uma experiência”.7

A especificidade da percepção estética, contudo, não a isola de outras regiões da experiência, pois não há uma cisão irreparável entre a vida de todos os dias e aqueles acontecimentos que, em sua dimensão estética, permaneceriam

\footnotetext{
${ }^{6}$ SEEL. L'art de diviser. Le concept de rationalité esthétique, p. 123.

${ }^{7}$ SEEL. L'art de diviser. Le concept de rationalité esthétique, p. 60.
} 
desvinculados e colocados hierarquicamente acima das atitudes que tomamos em resposta a outras situações experimentadas habitualmente. Ainda assim, a experiência estética traz consigo uma negatividade fundamental: fazer uma experiência não significa nem simplesmente recorrer ao já sabido nem adotar, imediatamente, o que é desconhecido: a experiência procura integrar o que é estranho ao familiar (isto é, ao quadro de referências que era familiar), mas alargando e enriquecendo aquilo que até então constituía o limite de todo real possível. ${ }^{8}$ Como resposta a uma "coerção acontecimental”, a experiência estética é uma mobilização multidimensional (cognitiva, volitiva e emotiva), produzida no confronto com um objeto problemático que é experimentado em uma situação nãofamiliar. Seel denomina comunicação presentificante a esse modo de articulação do sentido que, vinculado a uma situação e baseado em um conjunto de pressuposições compartilhadas, permite alargar e corrigir uma pré-compreensão dada ou ainda introduzir, de maneira provocadora, um ponto de vista desviante.

Não temos como expor, em sua inteireza, a perspectiva de Seel. Digamos, por ora, que seus esforços compartilham das esperanças daqueles estudos que, nos últimos vinte anos, procuraram renovar a abordagem da Estética. Segundo JeanMarie Schaeffer, as abordagens do tema conduzidas pela lógica, semiótica, filosofia cognitiva, filosofia da linguagem, antropologia, sociologia, psicologia - dentre outras disciplinas - estilhaçaram o cimento unificador da Estética enquanto doutrina filosófica. Schaeffer ressalta que seu diagnóstico, sem pretender abarcar a totalidade das diversas reflexões e estudos dedicados à experiência estética, concerne unicamente a uma figura filosófica em particular, construída historicamente, devidamente canonizada e guiada pela conjunção de três princípios: a) a preocupação com a objetividade ou com a validade do julgamento estético; b) a busca, pela filosofia da arte, em assentar a ontologia das obras em critérios de valor; c) a redução da dimensão estética à dimensão artística. ${ }^{9}$ A força da doutrina estética reside na atração psicológica exercida pela oposição ontológica que ela constrói entre "a condição humana efetivamente vivida e um modo de ser

\footnotetext{
${ }^{8}$ Seel recorre a uma concepção de experiência que se vale tanto da hermenêutica (Gadamer) quanto do pragmatismo (Dewey). Cf. SEEL, L'art de diviser. Le concept de rationalité esthétique, p. 66-79.

${ }^{9}$ SCHAEFFER. Adieu à l'esthétique, p. 3.
} 
que, sob uma forma ou outra (acesso a um estado contemplativo universalmente compartilhado, a uma plenitude do ser ou a uma verdade extática), é suposto como capaz de escapar a essa condição”. ${ }^{10}$

\section{O pathos da vida ordinária}

Podemos aventar, contudo, a hipótese de não foi preciso esperar a teoria ou a crítica para anunciar e sancionar um programa filosófico capaz de compreender a experiência estética sob um novo ponto de vista. Foram as obras mesmo que, sem esperar que sua verdade pudesse ser traduzida pelo discurso filosófico, começaram a problematizar as condições e os recursos expressivos de que dispunham para produzir a experiência intensificadora e inefável da qual um dia foram encarregadas. Leitor do "purista” Paul Valéry (aos olhos de Seel), Carlos Drummond de Andrade, cuja poesia sempre freqüentou os prosaicos materiais da vida, expressou essas novas condições da experiência estética em um poema intitulado "Música barata".

Paloma, Violetera, Feuilles Mortes

Saudades do Matão e de mais quem?

A música barata me visita

e me conduz

para um pobre nirvana à minha imagem.

(....)

Não quero Handel para meu amigo

nem ouço a matinada dos arcanjos.

Basta-me

o que veio da rua, sem mensagem,

e, como nos perdemos, se perdeu. ${ }^{11}$

"Um pobre nirvana à minha imagem" - essa expressão poderia facilmente alimentar as discussões em torno do empobrecimento de toda experiência e por extensão, da experiência estética. Sob esse ponto de vista, o poema seria a

\footnotetext{
${ }^{10}$ SCHAEFFER. Adieu à l'esthétique, p. 5.

${ }^{11}$ Este poema aparece na seção "4 poemas", incluídos em José \& outros. Utilizamos a edição de Reunião 10 livros de poesia de Carlos Drummond de Andrade. Rio de Janeiro: Livraria José Olympio Editora, 1976, p. 279.
} 
expressão perfeita da "vida pobre", a começar pelo embotamento dos sentidos e do estreitamento dos mundos possíveis oferecidos não mais pela arte - exilada ou muda em sua recusa da vida ordinária - mas pelos novos meios de reprodutibilidade técnica, o rádio e o disco, que disseminariam uma forma de experiência estética degradada, incapaz ou impedida de transfigurar o banal ou dele extrair qualquer forma de revelação. Contudo, ao contrário de uma descrição negativa da pretensa inautencidade da experiência fornecida pela "música barata", o que o poema faz é aproximar a experiência da arte das percepções e das sensibilidades ordinárias, o que é próprio daquilo que Jacques Rancière denominou "regime estético das artes".

Para o autor, este regime possui uma racionalidade cuja complexidade não pode ser simplesmente decretada pelo discurso filosófico, e diz respeito tanto aos critérios imanentes de produção artística quanto às forças que inscrevem nas obras a marca do Outro: "respiração de uma sociedade, sedimentação da matéria, trabalho do pensamento inconsciente”. Para Rancière, este regime estético das artes é guiado por uma tensão entre dois pares de contrários: ao mesmo tempo em que ele identifica a potência da arte ao imediato de uma presença sensível, também faz entrar na vida das obras o trabalho da crítica que as altera e lhes concede re-escrituras e metamorfoses diversas; ele afirma a autonomia da arte e também multiplica a descoberta de belezas inéditas nos objetos da vida ordinária ou apaga a distinção entre as formas de arte e aquelas outras do comércio ou da vida coletiva. ${ }^{12}$ Tornou-se impossível devolver a arte a ela mesma, e as obras resistem em serem tomadas unicamente como propiciadoras de julgamentos estéticos que, muito rapidamente, servem unicamente à própria visada dos seus intérpretes. Para Rancière, a identificação das práticas artísticas sempre derivou de uma inteligibilidade que as vincula a outras esferas da experiência. ${ }^{13}$

Será que essa nova dimensão concedida à experiência estética, conduzida pela própria arte, às expensas da Estética, encontrou ecos naquelas investigações que, recentemente, segundo Jean-Marie Schaeffer, dispersaram os objetos e os fatos estéticos entre os mais diversos saberes? Em seu "adeus à Estética",

\footnotetext{
${ }^{12}$ RANCIÈRE, Jacques. Le ressentiment anti-esthétique. Magazine Littéraire, n. 414, nov. 2002, p. 19.
} 
Schaeffer, apoiado nas ciências cognitivas, adota uma perspectiva analítica cuja tarefa será simplesmente a de identificar e compreender os fatos estéticos, e não propor um ideal estético ou critérios de julgamento. Trata-se de uma operação de depuração extrema, cujos acertos e insuficiências deverão ser avaliados minuciosamente. Para esta outra visada do domínio estético - que não concerne unicamente às obras de arte,- o traço definidor dos fatos estéticos é deslocado da propriedade interna dos objetos (caução recorrente nas definições que almejam alcançar a essência da arte) para sua dimensão relacional, isto é, para um tipo de conduta que "investe" de tal modo nossa relação com os objetos e as situações que lhes permitem ser experimentados esteticamente. Para tanto, Schaeffer caracteriza a conduta estética como uma atividade representacional (de natureza mental), marcada pela intencionalidade e dona dos seguintes atributos: a) ela comporta uma dimensão cognitiva que não se distingue inteiramente da nossa relação "banal” com o mundo; b) ela está assentada na percepção comum do mundo, e não em uma abordagem científica ou reflexiva. É o mundo que “age” sobre nós, isto é, que nos afeta e nos obriga a ajustar nossas representações a ele; c) quando nos entregamos a uma conduta estética, nossa atividade torna-se fonte de prazer; d) aquilo que constitui o objeto de nossa atenção é dotado de propriedades que lhe concedemos não através de uma crença ou de um julgamento, mas por meio dos afetos; e) a conduta cognitiva é uma conduta interessada: sua natureza apreciativa e valorativa está ancorada, em última instância, na economia de nossos desejos. ${ }^{14}$

A atividade cognitiva, que é o suporte de base da conduta estética, possui um caráter auto-teleológico; ela busca uma relação de satisfação que é endógena, porém, isso não vale para a conduta estética, que adquire funções variadas de acordo com seu pertencimento às diferentes culturas. O que importa frisar, por ora, é que a perspectiva de Schaeffer permite-nos determinar o lugar do julgamento de gosto na conduta estética sem derivá-lo do lugar que lhe é atribuído comumente na avaliação das obras de arte. $\mathrm{O}$ autor estabelece a distinção entre a apreciação (o estado afetivo causado pela atenção cognitiva) e o julgamento valorativo. Enquanto o primeiro tem uma função expressiva, destinado principalmente ao uso privado e

\footnotetext{
${ }^{13}$ RANCIÈRE, Jacques. Le ressentiment anti-esthétique. Magazine Littéraire, n. 414, nov. 2002, p. 21.
} 
se manifesta através de um ato de fala no qual a verdade da proposição é pressuposta, o segundo possui uma natureza argumentativa, que se manifesta publicamente no campo agonístico das disputas em torno da arte. O julgamento valorativo não é interno à relação estética e nem constitui sua finalidade, pois o ato judicatório mantém com ela uma relação externa. Afinal, aqueles que buscam a experiência estética não o fazem primordialmente a fim de participar na elaboração de um mundo hierarquizado da arte, o que exigiria um julgamento teleológico (destinado a avaliar a conformidade ou não do objeto estético a um modelo proposto) ou um julgamento normativo (para o qual essa conformidade do objeto ao modelo é tomada como desejável e objetivada em predicados de valor). ${ }^{15}$

Uma perspectiva como esta, que se propõe a "limpar o campo" e a se deter em um aspecto excessivamente delimitado da experiência estética - para melhor mantê-lo sob controle - pode trazer alguns ganhos para os estudos voltados para a compreensão da dimensão estética dos fenômenos comunicativos. (Mantenhamos sob reserva a indagação se a ênfase nas dimensões cognitiva e intencional da relação estética consegue abalar ou deslocar verdadeiramente as reivindicações da doutrina estética). Aceitemos que a proposta de Schaeffer permite, ao menos, descrever a experiência estética proporcionada pelos mais diferentes objetos e situações sem ter que caracterizá-la como uma figura - em negativo - contraposta à experiência - tomada como autêntica - fornecida pelas obras de arte (seja as das vanguardas históricas, do alto modernismo ou da arte dita contemporânea), devidamente corroboradas tanto pela história da arte quanto pela doutrina estética.

Entretanto, o problema acarretado por uma abordagem como esta é que um estudo rigorosamente descritivo da experiência estética, livre do encargo de pronunciar julgamentos valorativos e sem alimentar quaisquer expectativas acerca do que ela pode trazer à sensibilidade, aos universos imaginários e às práticas cotidianas dos seus fruidores, acaba por se mover em um território de indistinções. Ainda que o modelo de Schaeffer possa ser utilizado tanto para explicar a epifania

\footnotetext{
${ }^{14}$ SCHAEFFER. Adieu à l'esthétique, p. 26-30.

${ }^{15}$ SCHAEFFER. Adieu à l'esthétique, p. 68.
} 
em Joyce quanto a atividade de uma criança que se encanta ao contemplar o mundo diminuto das formigas, tal caracterização da conduta estética não alcança nada além de um circuito no qual a atenção, ludicamente recompensada pela satisfação, é reenviada circularmente à situação que lhe proporciona tal estado. Além de termos como "satisfação" ou "prazer", Schaeffer pouco escreve acerca do que a relação estética - além desse seu centramento auto-teleológico - pode oferecer em relação às outras experiências - não estéticas - e às outras situações e atitudes que sujeito poderia extrair daí.

Este modelo tão depurado, que quase nada pede à experiência estética nenhuma promessa, utopia alguma - para melhor estendê-la a múltiplos objetos e situações, que a destitui de qualquer superioridade frente ao banal, não corre ele o risco de cortar os vínculos entre a relação estética e o seu entorno, isto é, as demais atividades e situações que não possuem a mesma intencionalidade? Ainda que a arte não seja mais eleita como o modelo da experiência autêntica, ela parece ter sido muito rapidamente empurrada para o domínio do julgamento de gosto e aprisionada nos limites do sentido institucionalizado. Embora no início de seu livro Schaeffer lamente que os amadores dos quadrinhos e do rock do grupo Led Zepelin (!) continuem esquecidos por aqueles estudos que não se guiam mais pela doutrina estética, ele próprio, na terceira parte de Adieu à L'Esthétique, retorna a Kant para discutir como é que uma mesma atividade de atenção cognitiva concedida a um objeto pode dar lugar a diferentes tipos de julgamento. Enquanto as impurezas da experiência em geral e as possíveis interferências que a experiência estética podem trazer a outras regiões e situações vividas pelos sujeitos são afastados para o domínio intransferível e incomunicável da vida pessoal - na sua regulação do prazer - os experts, a crítica e o público especializado (com seus hábitos cuidadosamente educados), podem se entregar aos julgamentos estéticos e normativos... Quem sabe, ao invés de adotar um modelo de relação estética que cabe tanto a obras artísticas quanto a outros objetos que podem ganhar um caráter estético por força da intencionalidade que sobre eles incide, não seria possível buscar um outro modo de conceber a experiência estética, sem valorizá-la a partir 
da oposição ontológica entre a condição humana efetivamente vivida e aquilo que se supõe dotado do poder de ultrapassá-la?

Seria preciso ao menos indicar o que podemos esperar da experiência estética, agora que - nos termos de Schaeffer - os fatos estéticos não podem ser explicados

nem como exemplificação analógica (e sensível) da racionalidade filosófica nem como contra-modelo de completude e de autenticidade (em oposição a um modo de ser marcado pela falta e pela inautenticidade), nem como lugar de manifestação do fundamento transcendental da humanidade ou do florescimento de um modo de comunicação no qual a subjetividade individual e a universalidade da humanidade ressoariam em harmonia. ${ }^{16}$

Sem pretender - e nem poder - responder uma questão lançada assim ao final desta apresentação, sugiro, como um aceno, uma possibilidade de investigação a ser explorada, e que chega até mim pela escrita de Maria Gabriella Llansol. Em $O$ senhor de Herbais encontramos a seguinte indagação:

se é verdade que o mundo é feito de mundos estéticos, que destino dar à frase de Benjamin: "o mundo é a nossa tarefa"? (...) Creio que Benjamin ainda acreditava na distinção entre compreender e transformar, que herdamos dos Gregos. Não creio que tenha chegado a "ver" que o transformável é o esteticamente desdobrável, que o instrumento estético e cognitivo da literatura é central nessa operação e que a sua utilidade mais preciosa consiste na destrinça interactiva dos mundos. ${ }^{17}$

Que destino dar a estas frases de Llansol, senão desdobrá-las em um mundo ficcional que não nos retira daquele que habitamos, mas que nele entreabre um outro mundo? Dito assim parece tratar-se de apenas de mais uma metáfora, mas o que está em jogo aqui é o papel que se atribui à linguagem nessa operação poética de abrir mundos dentro do mundo, não separados, mas em interação. Penso naquela passagem de $O$ discurso filosófico da Modernidade na qual Habermas fala de uma "polaridade repleta de tensões entre a função poética e descobridora do mundo e as funções prosaicas e intramundanas da linguagem”, reivindicando que a primeira deve encontrar seu "ponto de apoio no processo comprovativo da práxis intramundana”. ${ }^{8}$ Como sabemos, se Habermas distingue bem essas duas funções é

\footnotetext{
${ }^{16}$ SCHAEFFER, Jean-Marie. Adieu à l'esthétique. Paris: PUF, 2000, p. 8.

${ }^{17}$ LLANSOL, Maria Gabriela. O senhor de Herbais.Lisboa: Relógio D’Água, 2002, p. 46.

${ }^{18}$ HABERMAS, Jurgen. O discurso filosófico da modernidade. Lisboa: Dom Quixote, 1990, p.194-196.
} 
não apenas para evitar a estetização exacerbada da linguagem, mas para reivindicar que as linguagens estéticas de abertura para o mundo (e criadoras de mundos) se legitimem no interior das regras da atividade comunicacional, como criticou Rancière. ${ }^{19}$

Quanto a Seel, embora a noção de racionalidade estética tenha sua origem na razão comunicativa, ele não reduz os tipos fundamentais de racionalidade às três dimensões de validade estabelecidas pela pragmática lingüística (verdade teórica, justeza moral e veracidade expressiva), concebidas como esferas de valores independentes umas em relação às outras. Esses tipos fundamentais de racionalidade se manifestam sob a forma de diferentes atitudes - teórica, instrumental, moral, preferencial e estética - mas de tal modo que, na legitimação deste ou daquele comportamento, os argumentos utilizados, ao reivindicarem diferentes formas de validade, permaneçam secretamente religados, por meio dos pressupostos em jogo e das atitudes assumidas em cada ocasião. Desse modo, a justificativa desta ou daquela atitude se vê confrontada criticamente com as outras com as quais ela se inter-relaciona.

No que diz respeito propriamente à atitude estética, Seel lhe atribui um elemento regulador não utópico (em contraposição, em particular, às perspectivas de Adorno e Benjamin). A experiência estética não encarna mais a utopia da experiência, as obras de arte, não são mais encarregadas de transcenderem a realidade atual e anteciparem uma vida infinitamente boa, bela e redimida. Sob esse ponto de vista, o interesse estético reside unicamente nele mesmo, destituído de toda finalidade ulterior: "O que nós queremos é reencontrar nossa própria experiência em uma experiência”, afirma Seel. E se essa experiência se distingue das práticas da vida ordinária, não é para condenar suas limitações e maneiras de ver - desmentindo-as em sua inautenticidade - mas sim, para confrontá-las e transformá-las.

Contudo, esse "programa forte" de defesa da racionalidade estética, permanece, em geral, vinculado aos mesmos objetos artísticos escolhidos pelos autores que ele critica. Está certo que, no livro de Seel, a ênfase é colocada na

\footnotetext{
${ }^{19}$ RANCIÈRE, Jacques. O desentendimento. Política e fillosofia. São Paulo: Ed. 43, 1996, p. 66.
} 
descrição de um modelo conceitual cerrado, mas o horizonte das práticas artísticas e das condutas estéticas que ele enxerga permanece fortemente atado ao alto modernismo, apesar de uma ou outra referência ao cinema e nenhuma menção aos inúmeros objetos e situações estéticas que permeiam nosso cotidiano, para além das paredes dos museus e das salas de concerto... Com relação a isso, é impossível não lembrar o quanto um daqueles crentes na dimensão utópica da experiência estética dedicava sua atenção aos mais diversos objetos: as fotografias de Atget, o camundongo Mickey, os filmes de Chaplin e Pudovkin, a poesia de Baudelaire, antigos brinquedos de madeira e livros infantis, o LunaPark, o panorama, o feitiço das mercadorias expostas nas galerias... Enfim, todos reconhecem aí logo a lista interminável dos objetos nos quais Benjamin buscou ou encontrou uma experiência estética....Se a utopia surgia aí, no mais das vezes era apenas por uma fresta, num átimo, num sopro. Quando Llansol retoma a frase de Benjamin - "O mundo é a nossa tarefa" - ela se distancia daquela utopia da experiência que Habermas e Seel tanto censuram e se aproxima muito mais do domínio da imanência que Giorgio Agamben descreveu do seguinte modo:

O mundo do feliz e do infeliz, o mundo do bom e do malvado contêm os mesmos estados de coisas, são, quanto ao ser-assim, perfeitamente idênticos. $\mathrm{O}$ justo não vive noutro mundo. $\mathrm{O}$ eleito e o condenado tem os mesmos membros. O corpo glorioso só pode ser o próprio corpo mortal. O que muda não são as coisas, mas os seus limites. É como se sobre elas estivesse agora suspensa qualquer coisa como uma auréola, uma glória. ${ }^{20}$

O mundo que constitui nossa tarefa, portanto, não é outro senão este daqui, desdobrado e transformado esteticamente.

${ }^{20}$ AGAMBEN, Giorgio. A comunidade que vem. Lisboa: Editorial Presença, 1993, p 73. 